\title{
Integrating Big Data Analytics, Systems Thinking and Viable Systems Approach Towards a Shift from Individual to Collective Intelligence and Collective Knowledge Systems
}

\author{
STEFANO ARMENIA \\ s.armenia@unilink.it \\ Link Campus University \\ FRANCESCA LOIA \\ francesca.loia@unina.it \\ University of Naples Federico II
}

\begin{abstract}
The growing complexity of social systems and the fast technology evolution make central the role of innovative information technologies in complex organisations geared towards collective intelligence processes among the various social actors and analytical tools. These are able to foster participants' knowledge, manage the feedback through a holistic approach and, hence, shift organisations from a plurality of voices to an interactive intelligence representing the ultimate identity of the organisation itself. In this regard, this paper aims to offer a model for managing external and internal knowledge to support the viability of the organisation (system) in the longer term. The study adopts the interpretative lens provided by Systems Thinking, System Dynamics and Viable System Approach (vSa) to investigate the challenging domain of knowledge and information management for complex systems such as organisations. Therefore, a qualitative and interpretative approach has been chosen to reflect upon Big Data approaches and Collective Knowledge Systems (CKS), embracing a system perspective. The proposed conceptual model shows the crucial role played by the holistic managing of the external and internal knowledge that permits the alignment of the information variety of the organisation to the context and the entities that compose it in order to create harmonic relations. Leveraging on the concepts of vicariance, bricolage and exaptation, several advantages emerge that correlate to the complex system's ability to reach a greater level of survival by adapting and dynamically evolving itself. The ensuing investigation shows how Systems Thinking and Viable System Approach can provide deep insights into the field of information technology, evidencing the systems thinking contribution in analysing, understanding and managing dimensions and paths of social dynamics. A contribution to previous studies is provided with reference to themes such as Big Data, information and knowledge management.
\end{abstract}




\section{Introduction}

The last decade has seen growing attention devoted to social systems increasingly characterised by expanding complexity. Not only the rapid growth of the global economy, together with high population growth and the excessive exploitation of natural resources but also the ever-faster technological evolution underlines the need for a new holistic approach that allows the understanding of the complexity of organisations in the post-growth era (Dominici et al., 2016). In such a complex and fragmented context, the shift from an 'objective rationality' to a lower level of the intended rationality (Simon, 1955) highlights the limits of human decisions in terms of restricted available information, its cognitive limitations and limited time available.

On the basis of a system thinking approach, it is possible to act wisely by taking advantage of the information feedback about the external context and, through this, redefine the decisions and the mental models established. Unfortunately, the feedback mechanisms are quite inadequate and ambiguous, and new approaches aimed to enhance the learning of complex systems must be addressed, considering new tools able to foster the participant knowledge, articulate and reframe external perceptions and manage the feedback obtained by those perceptions through a holistic approach (Sterman, 1994).

Moreover, the importance of information and knowledge in every economic and social process has led to the so-called 'knowledge economy' (Powell and Snellman, 2004). Learning and knowledge creation are seen as qualitative relation processes that are sensitive and intellectual, creative and destructive, enabling and binding. These considerations call into question the belief that organisational knowledge is essentially codified and centralised, highlighting instead that organisational knowledge is included in the relationships between a plurality of people inside the organisation and between the organisation and the context (Stacey, 2003). Therefore, the tacit knowledge of relevant actors in the organisation assumes more and more importance in organisational learning and innovation processes, becoming the focus of considerable attention in the recent literature. However, such a view is missing a conceptual framework integrating micro-level learning activities (from the plurality of members) with organisational forms and macro-level (hence leading to a superior identity) societal institutions (Lam, 2000).

Thus, the need to manage together the potential information coming from outside, so as to combine in an equal way the codified and tacit knowledge, stimulates a new way of intending the information and knowledge management in the complex systems. Through the metaphors of exaptation (Gould and Vrba, 1982), bricolage (Lévi-Strauss, 1962) and vicariance (Reuchlin, 1978; Berthoz, 2013), new systemic and structural properties can be considered, able to guarantee a greater level of survival of the system in the context in which it operates. According to this, the growth of a system arises not only through an engineering activity but by processes of collective intelligence (Lévy and Bononno, 1997), able to help the organisations to carry out a participatory logic that can guide towards a common purpose and increase the viability of the complex system (Barile and Saviano, 2011).

With the aim to propose a conceptual model able to manage external and internal knowledge, the following study adopts the interpretative lens offered by the Viable System Approach (vSa) and Systems Thinking and, leveraging on the concept of Collective Intelligence and Collective Knowledge Systems (CKS), offers a framework that permits to align the information variety of the organisation to the external and internal entities in order to create harmonic relations 
(Barile and Polese, 2010). Therefore, system thinking, system dynamics and viable system approaches act as the theoretical background, merging in a single model different key concepts and explaining the shift from individual to collective intelligence and collective knowledge systems. In particular, from system dynamics, the concept of feedback is essential for enabling the combination of the different types of knowledge in a synergic way by means of an improvement cycle (Iandolo et al., 2018). On the other hand, the Viable System Approach (vSa) underlines the importance of adopting a participatory logic that can guide complex systems towards a common purpose to increase the viability of the system complexity and deal with numerous and changing entities of the external and internal context.

The present paper is comprised of four main sections. Firstly, it opens with the analysis of the theoretical background of reference, reporting the scientific evidence emerging from the literature on organisations as complex systems, the characteristics of these correlated to the metaphoric concepts of vicariance, bricolage and exaptation, and the new challenges in information technology. In the next section, the research line, structured by adopting the concepts provided by Systems Thinking and Viable System Approach, defines a new possible interpretative path with reference to the role of the external and internal knowledge in complex systems by highlighting the crucial role of the Collective Intelligence and Collective Knowledge. Afterwards, the potential implications of the work are highlighted and commented from both a theoretical-scientific and a practical-managerial point of view. Finally, the concluding remarks underline the limitations of the work carried out and offer suggestions for future research.

\subsection{Organisation and knowledge management as a complex system}

Typified by semi-autonomous organisational members interacting at many levels of cognition and action, business organisations can be represented by the generic constructs and driving mechanisms of complex adaptive systems theory (Dooley, 1997). Starting from the application of the complex system to the study of organisations and social behaviour, organisations are assumed to exhibit non-linear behaviour and should be used to provide context-specific descriptions of organisational behaviour with more historical, longitudinal and qualitative research methods (Svyantek and Brown, 2000). Complex systems face complex problems, and the human mind comes across different limits due to the restricted available information, its cognitive limitations and the limited time available to take any decision. Hence, this context does not allow to achieve the ideal of 'objective rationality' (i.e., make the most optimal decision possible, given the information available) and is destined to a lower level of the intended rationality (Simon, 1955). Consequently, the performance and success of an organisation are governed primarily by the limitations of its members and depend on the organisational setting within which decision-making takes place (Morecroft, 1983).

Nowadays, the value co-creation process for organisations is not a supplier-centric process of production and delivery, nor is it customer-centric; rather, it is more complex and dynamic. By examining participants in the creative process, the value is created by and for all the actors through a choral win-win perspective. Indeed, the involvement of several actors (such as customers, suppliers and partners) makes value co-creation a complex process (Gummesson, 2008; Gummesson and Mele, 2010; Polese, Mele and Gummesson, 2017). Therefore, as the complexity of the systems we live in grows, so do the unanticipated side effects of human actions, further increasing complexity. Effective methods for learning in and about complex 
dynamic systems are, for instance, tools to produce participant knowledge, articulate and reframe perceptions, and create maps of the feedback structure of a problem from those perceptions (Sterman, 1994).

There is a growing awareness by organisations that need to develop a capacity to increase their knowledge and learn from the previously mentioned complex dynamic systems. This process needs to be improved for people to understand the nature of their organisation, how it works, and the role of information and knowledge within it. This includes the creation of a sound understanding and practice of knowledge management (Alavi and Leidner, 2001). In particular, knowledge management can be defined as the creation of knowledge and its interpretation, dissemination, application, retention and refinement (De Jarnett, 1996). Often, it is seen as a critical source of competitive advantage (Allee, 1997), and it creates intellectual capital (Drucker, 1995). McAdam and McCreedy (1999) have explored a variety of knowledge management models, and one of the most interesting is provided by Nonaka and Takeuchi (1995). Indeed, Nonaka and Takeuchi (1995) develop their definitions of explicit and tacit knowledge to create the well-known SECI model for knowledge creation. It derives from the idea that a mapping or conversion process occurs between tacit and explicit knowledge, resulting in four types of knowledge conversion. Each of these can be regarded as a knowledge translation process. Another essential aspect of knowledge management concerns information management (Laudon and Laudon, 1999, 2011). The relation between information and knowledge is essential to organisations, not only as a resource (Liew, 2007). Information is related to data in that the latter may be regarded as measurements of perceived phenomena (Frakes and Baeza-Yates, 1992). Information is manifested through structured methods of inquiry (both for structured and unstructured data), and in the systems' domain, there has been a great deal of exploration into methods that create information. Therefore, knowledge is a driver of organisational awareness and viability, and can occur as a transformation of acquired information from environmental phenomena or virtually from forms of communication through which members of the community interact.

Thus, complexity can be addressed through information manifestation and knowledge creation, allowing organisations to develop greater viability. In this sense, the organisations aim to manage complex situations and make their knowledge clear and less uncertain to survive in the longer term. Indeed, on the basis of the approach to knowledge creation cycle by Nonaka and Takeuchi (1995), grounded on a constructivist process through a positivist structure, a different critical approach for knowledge creation comes from viable systems, which does not see knowledge creation as a set of sequential steps, but rather as a set of phases that are constantly tested and examined through possibly complex feedbacks (Yolles, 2000, 2006). Therefore, knowledge management fits in the larger context of systems thinking so that the influencing factors on its success or failure can be better recognised and understood (Rubenstein-Montano et al., 2001).

\subsection{Complex system characteristics behind the lens of metaphors}

Starting from the application of the complex system to the study of organisations and social behaviour, organisations are assumed to exhibit non-linear behaviour and should be used to provide context-specific descriptions of organisational behaviour with more historical, longitudinal and qualitative research methods (Svyantek and Brown, 2000). 
In general, complex systems possess peculiar characteristics that determine their level of complexity and their functioning. In her book, Thinking in Systems, Donella Meadows (2008) describes these distinctive properties of complex systems and how they permeate complex systems of every kind and in every context. If we want to draw a parallelism, the properties mentioned by Meadows (2008), that is, self-organisation, hierarchy and resilience, have strong points in common with three key concepts that could easily serve as a metaphor for the study of management of organisations, which can be regarded, as previously said, as full-fledged complex systems. The three key concepts are exaptation, vicariance and bricolage. They have a unique one-to-one relationship with the complex systems' properties mentioned by Meadows (2008), as shown in Table 1.2.1. The reason for these parallelisms lies in their definitions.

The exaptation (Gould and Vrba, 1982) is a particular type of evolution in which an evolved character for a particular function assumes a new function, independent of the primitive. For instance, the feathers of the birds, evolved from the dinosaurs presumably for thermal isolation and balance, have changed their purpose, becoming fundamental for flight. This is a perfect example of the self-organisation capacity that determines the process of evolution of species, which is governed by specific laws (Von Bertalanffy, 1952). These self-constituted laws emerge from the stimulus for the survival and adaptation of the biological system which, as a complex system, evolves and adapts, making its structures more intricate, diversified and independently seeking the best possible structure to continue to exist.

The diversification operated naturally by complex systems has much to do with the concept of vicariance. In biological terms, the vicariance (Reuchlin, 1978; Berthoz, 2013) can be defined as the fragmentation of an environment as a factor in promoting biological evolution by dividing large populations into isolated subpopulations. Therefore, from a systemic point of view, the process of diversification and vicariance leads to the creation of a spontaneous organisation in systems and subsystems, according to a hierarchical order. As a result, larger systems often coordinate smaller ones, which maintain themselves and the broader system, creating stable, efficient and resilient structures.

Finally, the concept of bricolage has something in common with resilience. As Lévi-Strauss (1962) states, the universe of available tools is limited for the bricoleur. For the bricoleur, the rule of the game consists in constantly adapting to the set of resources at her/his disposal, which are the contingent result of all the opportunities encountered to renew or enrich her/his resource stock, to find all the possible answers that her/his set can offer for resolving a specific problem. The ability to dynamically use resources to face problems and changes is typical of complex systems that regulate themselves and aim for a balance. The same balance which is central when talking about the resilience of a complex system is the ability of a system to survive and maintain steadiness within an unstable environment by combining available resources and optimising their use.

Therefore, complex organisations should follow a conceptual model able to exploit these properties in order to achieve an advantage in the long run and encourage the value cocreation process.

Exaptation $\quad$ Vicariance $\quad$ Bricolage


The shift of a trait in the function during the evolutionary process from both an anatomical and behavioural perspective (Gould and Vrba, 1982).

\section{Meaning}

\begin{tabular}{|c|c|}
\hline & Self-organisation \\
\hline & $\begin{array}{l}\text { The capacity to emerge over } \\
\text { time in a coherent form. It } \\
\text { adapts and organises itself to } \\
\text { guarantee adaptation without } \\
\text { some singular entity capable } \\
\text { of managing it or controlling } \\
\text { it deliberately. }\end{array}$ \\
\hline $\begin{array}{l}\text { Complex } \\
\text { system } \\
\text { properties }\end{array}$ & $\begin{array}{l}\text { Constant redefinition of the } \\
\text { relationship between the } \\
\text { system and its environment } \\
\text { (i.e., co-evolution) (Holland, } \\
\text { 1995). }\end{array}$ \\
\hline
\end{tabular}

Table 1.2.1. Merging the complex system properties with metaphors of exaptation, vicariance and bricolage. ${ }^{1}$
Hierarchy
The hierarchical structure maintains a certain degree of control, but it entails continuous internal reorganisation because the complex systems adapt their behaviour in relation to the changes that occur both internally between the agents that compose them, and externally, in the context in which they are inserted.
The system evolves incessantly over time while maintaining its own coherence, the 'identity' of the entire system, without disintegrating (Levin, 1998).

The substitution of a According to Lévi Strauss process with another process leading to the same result.

It is a fundamental tool for organisms because it offers them the powerful ability to create, innovate and interact with others in a flexible, broadminded and generous way (Reuchlin, 1978; Berthoz, 2013).
(1962), the bricoleur is the one who uses the tools that $\mathrm{s} / \mathrm{he}$ finds around her/him and tries to adapt such tools according to various attempts to her/his purposes.

Furthermore, the author distinguishes between the savant (the scientist) and the bricoleur for the inverse functions that, in the instrumental and final order, they assign to the event and the structure. Indeed, the former brings to light the events through the structures; the latter, the structures through the events.

\section{Resilience}

The property of complex systems to restore functioning mechanisms by responding to stress phenomena. Resilient systems react by renewing themselves while retaining the systems' recognisability. Resilience implies the restoration not of the initial state but the functionality through adaptation (Holling, 1996; Holling and Gunderson, 2002). 


\subsection{Big Data analytics as a competitive driver for complex organisations}

Nowadays, starting from the issue of the limited information available in the decisionmaking process, the higher and quicker development of always better data management technologies in complex organisations have recently contributed to rendering cheaper and faster the activity of gathering and processing large amounts of data with reference to specific process and performance indicators. This new paradigm, represented by the Big Data phenomenon, is definitely exploding, denoting a new era in data exploration and utilisation (Chen et al., 2012). The 'mass digitisation' (Coyle, 2006) connected to 'Internet of Things' interconnection (Ashton, 2009) led to a rapid expansion of large amounts of data, characterised by three dimensions: volume, speed and variety of generated data, as reported by Laney's 3Vs model (Zikopoulos and Eaton, 2011; Beyer and Laney, 2012; Zaslavsky et al., 2013). Later, other concepts, such as veracity and value, have been attributed to this model to highlight respectively the quality across datasets and the capacity to generate helpful output for industry challenges and issues (Uddin and Gupta, 2014).

Several techniques, technologies, practices and methodologies are already being used in each sub-process related to a data-driven application, which comprises transmission, capture, storage, analysis, visualisation and interpretation to improve decision-making processes (LaValle et al., 2010; Chen and Zhang, 2014). As a result, decisions will increasingly be based on data and analysis rather than experience and intuition (McAfee and Brynjolfsson, 2012). Towards this scope, the data mining techniques permit the extraction of valuable information from large datasets or streams of data (Fan and Bifet, 2013) and can reveal insights, thus supporting decision-making processes. Indeed, the data-driven model involves demanddriven aggregation of information sources, mining and analysis, user interest modelling, and security and privacy considerations ( $\mathrm{Wu}$ et al., 2014). Consequently, through data mining techniques, the purpose is to analyse structured and unstructured data and create information, becoming a strategic activity able to create knowledge and value for companies (Rowley, 2007; Cricelli and Grimaldi, 2008).

Thus, the proliferation of big data and the speed of analytics are significantly disrupting many business models, regarding information as an asset that will transform business and operating models (Armenia et al., 2017; Ciasullo et al., 2018; Troisi et al., 2018). The big data movement offers many unique opportunities for organisations considered as complex systems, such as benefiting from knowledge discovery and management process, exploiting big data techniques, cloud computing and semantic web in order to offer a broader spectrum of pervasive knowledge acquisition to enrich users' experience in learning (Begoli and Horey, 2012). In this regard, several organisations do not yet understand how to use the best analytics to improve business performance and manage risk since the skills required are yet limited and strategic priorities are focused on other challenges, including legacy IT systems (Johnson, 2012). Therefore, structural and systemic management efforts will be needed to create a new performance culture for the organisation, including skills, capabilities and infrastructure. Indeed, if appropriately managed and implemented, data analytics can bring clarity to business decisions and improve business outcomes by helping leaders to focus on the knowledge they need, derive insights and actionable intelligence from data and create, manage, and govern new business models (Prescott, 2014).

Hence, organisations considered as complex systems are facing new challenges based on new information technology and are looking for ways to exploit the potentialities of big data to 
improve their decision-making processes in order to take advantage of an evolutionary process in which the gradual understanding of the potential of big data and the 'routinisation' of processes play a crucial role (Janssen, Van Der Voort, and Wahyudi, 2017). Indeed, considering the exponential growth in data, enterprises must make the most of the vast data landscape by applying multiple technologies, carefully selecting key data for specific investigations and innovatively tailoring large integrated datasets to support specific queries and analyses. All these actions flow from a value chain framework based on data that enables the management of data holistically, from capturing to supporting decision-making and the variety of stakeholders (Miller and Mork, 2013).

In complex organisations, this innovative information technology is oriented towards collective intelligence processes among the various social actors and analytical tools. These are able to foster the participant knowledge, manage the feedback through a holistic approach and, hence, shift organisations from a plurality of voices to an interactive intelligence representing the ultimate identity of the organisation itself. However, internal knowledge should also regain a crucial role in the knowledge dynamics of organisations by contributing to the decision-making process and the improvement of the level of awareness regarding internal potentialities, limits and structural characteristics (Cohen et al., 1985; Ten Berge and Van Hezewijk, 1999). In this direction, organisations as complex systems can pursue viability in the longer term by exploiting new information technologies for obtaining external knowledge and by taking advantage of internal knowledge.

\section{Methodology}

Starting from the premises introduced in the previous section, the present paper is based on a qualitative approach method in order to provide valuable insights for managing the internal and external knowledge for complex systems. The choice to adopt a qualitative approach is based on the nature of the investigated field (Lincoln and Denzin, 1994). Indeed, the analytical and reductionist approaches are restricted enough for the analysis of complex systems. This underlines the need to follow a system approach to highlight a whole set of phenomena and offer a clear picture of its structure and functioning. In order to fill this gap, the paper adopts the interpretative lens provided by system thinking, system dynamics and viable system approach so as to merge in a single model different key concepts. Indeed, from system dynamics, the concept of feedback covers a central role in the following model since it enables the combination of the different types of knowledge in a synergic way by means of an improvement cycle (Iandolo et al., 2018). On the other hand, the Viable System Approach underlines the necessary participatory logic that can guide complex systems towards a common purpose to increase the viability of the system's complexity and deal with numerous and changing internal and external context entities. Subsequently, the concepts of Collective Intelligence and Collective Knowledge Systems are recalled as a first model in order to take into account the crucial role of the social web and build the viable framework for managing internal and external knowledge.

\subsection{Systems Thinking and System Dynamics}


At this stage of our study, one of the methodologies introduced in the definition of the proposed framework is based on a qualitative modelling approach named Causal Loop Diagrams (CLD). This is one of the primary tools in Systems Thinking, which in turn is typical of the initial qualitative design phase in the System Dynamics modelling and simulation approach (Sterman, 2001). Furthermore, System Dynamics (SD), proposed by Forrester (1961), is deeply rooted in the General System Theory (GST), proposed by Von Bertalanffy (1956), as well as in the theory of feedback control from systems engineering.

GST was developed from the need to make more 'scientific' the behavioural, biological and psychosocial sciences so that their concepts and theories could be appreciated as well as the ones of physics and mathematics (Von Bertalanffy, 1967). In GST, the essential condition to define a system, the one that makes it maintain its status of being a 'system', is that its elements interact with each other. More elements interact when one influences the other, for example, by exchanging energy during shocks, performing different functions in an electronic circuit, and exchanging information as in social systems. The stability of the system property is due to continuous interaction.

John Sterman (2012) describes System Dynamics as the founding element for creating and designing a new systems science inside a fragmented academy and polarised world, hence also arguing that SD can constitute an 'Esperanto' for systems researchers in talking the same language.

Besides the fact that firms can be considered complex systems and, as such, they are good subjects for investigation from a systemic approach, the link between the SD approach and the general theory of the firm is then clear. Indeed, the SD approach was designed by Forrester in 1961 in his first seminal book Industrial Dynamics, where he was basically arguing how a company can achieve sustainable growth only by considering the interdependencies between the economic and social systems. This implies putting what is called 'soft' variables (typical of human behaviour in decision-making) at the centre of a systemic and behavioural view of the firm. This, of course, is strictly connected to the work done in the early 1960s at Carnegie Mellon on organisational theory (Cyert and March, 1963), from which Forrester later formalised the delay between information and action. Being also a simulation approach to the analysis of dynamic systems, SD often adopts a numerical rather than an analytic approach to investigating the systems' behaviour. This implies that SD escapes the rigidities imposed by the need for closed-form solutions, implying simplified mathematical formulations amenable to analytical solutions. On the contrary, SD is not constrained by the limits imposed by closedform solutions and can, therefore, adopt richer formalisations. Through simulation, SD allows investigating the behaviour of complex systems (including the one tightly linked to societal aspects/issues); furthermore, it deals with the decision-making problem in business, industry, economy, etc. (Sterman, 2000). The features of SD include the possibility to account (in the description of a system or a system of systems) for aspects like non-linearities, information feedbacks, time delays, interdependency between subsystems and dynamic complexity (O'Connor and McDermott, 1997). The SD approach employs various tools for extrapolating information about complex systems and discovering hidden and counter-intuitive behaviours.

In this sense, the CLD approach, typical of the Systems Thinking approach, is heavily qualitative but is the starting point for the production of a quantitative model. However, notwithstanding its qualitative value, the analysis of CLDs can introduce several key results. The first advantage in using this type of analysis is that it provides a view that considers many 
themes inside a system as interconnected with each other, contrary to those past approaches where systems are analysed individually and on a sectoral basis.

The outcome of a CLD is a combination of causal links between variables. Links can be of two types:

1. Positive (S): when the independent variable (i.e., arrow tail) changes, then the dependent variable (i.e., arrow head) changes in the same direction;

2. Negative $(\mathrm{O})$ : when the independent variable (i.e., arrow tail) changes, then the dependent variable (i.e., arrow head) changes in the opposite direction.

There are two types of feedback loops: reinforcing and balancing feedback loops (indicated by + and - inside the loop). Also, it is possible to indicate a time delay between the two variables (see Figure 2.1.1):
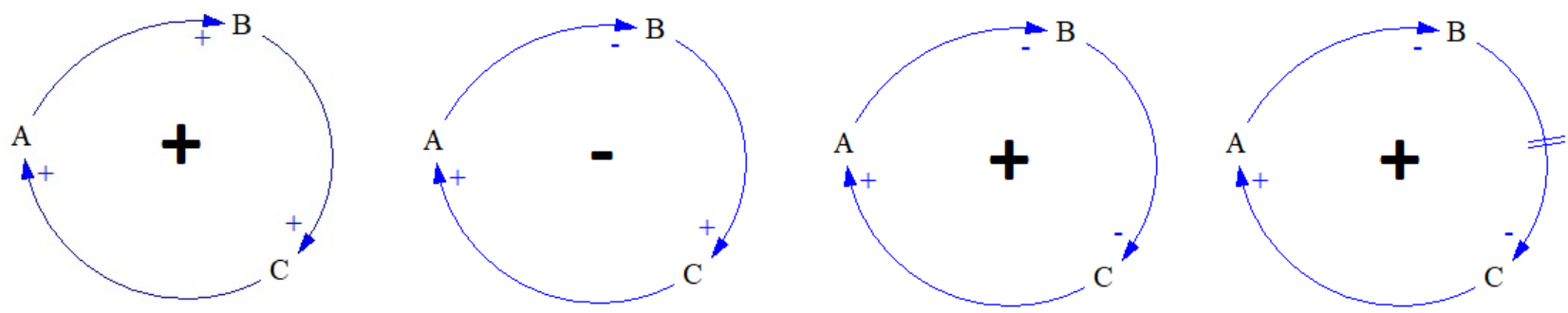

Figure 2.1.1. Starting from the left: Positive loop, negative loop, positive loop due to even number of negative links and delayed loop.

In a reinforcing feedback loop, the effects of a minor disturbance on one or more variables inside the loop cause an overall increase in the magnitude of the perturbation. As a result, this type of loop often produces exponential growth, increasing oscillations, chaotic behaviour, or other divergences from equilibrium. Conversely, a balancing feedback loop tends to promote a settling to equilibrium, reducing the effects of possible perturbations that have affected one or more variables inside the loop. However, the concept of feedback is essential for complex organisations, especially for enabling the combination of the different types of knowledge in a synergic way by means of an improvement cycle (Iandolo et al., 2018).

Positive, negative and delayed loops can generate a variety of systemic structures, named system archetypes, which can assist in taking a closer look at the problem displayed by a specific system and diagnosing the optimal solution (Mirchi et al., 2012). Systemic archetypes are modular structures that highlight a particular behavioural pattern. They can be used, individually or together with others, to infer a set of behaviours that can be found in the evolving observable variables of a system (Senge, 1990: 93):

If reinforcing and balancing feedback and delays are like the nouns and verbs of systems thinking, then the systems archetypes are analogous to basic sentences or simple stories that get retold again and again.

Therefore, by founding these types of patterns inside a system, it is possible to give a deeper explanation about its dynamics and performance (Armenia et al., 2013). 


\subsection{Systems Thinking and Viable System Approach}

Recognising the limits of the traditional analytical-reductionist approach for complex systems, this paper follows a systemic approach, underlining the need for providing a complete account of phenomena. In this way, the systems path appears as a bridge between a reductionist and a holistic approach (Barile and Saviano, 2011). Indeed, the Viable System Approach (vSa), by re-exploring the contributions of system thinking to management, can be considered as a set of lenses for observing complex phenomena, focusing on the analysis of relationships among socio-economic entities in the context which seek viable interacting conditions (Barile and Saviano, 2008; Golinelli, 2010). Furthermore, given the complexity for organisations, the vSa can support the process of decision-making (Barile and Saviano, 2018) by basing decisions on a participatory logic that can act as a guide towards a shared goal. In particular, considering the survival as the primary purpose of a system (i.e., 'system viability'; see Barile et al., 2012), the system in order to survive tries to be aligned (i.e., be consonant) with its relevant supra-systems (i.e., other systems that retain critical; see Polese, Mele and Gummesson, 2017). The concepts of consonance between two systems (individuals, social systems, etc.) can be analysed by means of the model of information variety (Ashby, 1991), which accounts for the symmetry of information varieties among the involved entities.

The information variety, as shown in Figure 2.2.1, has the following three dimensions (Barile, Saviano and Polese, 2014):

- $\quad$ information units, which is the number of single units of data detained by a system (i.e., the structural knowledge of the system);

- $\quad$ interpretation schemes, or the cognitive schemes according to which the information units are assembled and understood (i.e., the knowledge 'shape' of the system) based on the context;

- categorical values, which are the system's basic values and strong beliefs (i.e., the resistance to change) that influence how the interpretative schemes are used.

The role of the categorical values is particularly relevant since they are responsible for allowing and directing interaction, the degree of system openness, the information sharing process and the outcome of the interaction. In sum, the categorical values finally determine the overall degree of consonance (Barile, Saviano and Polese, 2014). Thus, in order to reach a greater level of consonance, the system should consider the variety of expectations of external systems considered relevant, allowing for greater awareness of the interventions that could be aimed for reaching a greater level of consonance and ensure viability in the reference context. To this end, incorporating the social community into the decision support systems processes (Wu et al., 2018) can help the organisations to carry out a participatory logic that can guide towards a common purpose and increase the viability of the system complex. Therefore, it is necessary to look for solutions that can support the decision-making process, which finds itself dealing with numerous and changing entities of the context in conditions of complexity, in an attempt to harmonise the interests of the various actors and converge towards a joint evolutionary direction, that is, towards the context consonance (Barile and Calabrese, 2011). In this direction, the technologies can be considered a strategic driver that allows users to communicate so as to align their information variety and improve the context consonance and the viability of the system (Barile et al., 2018). 


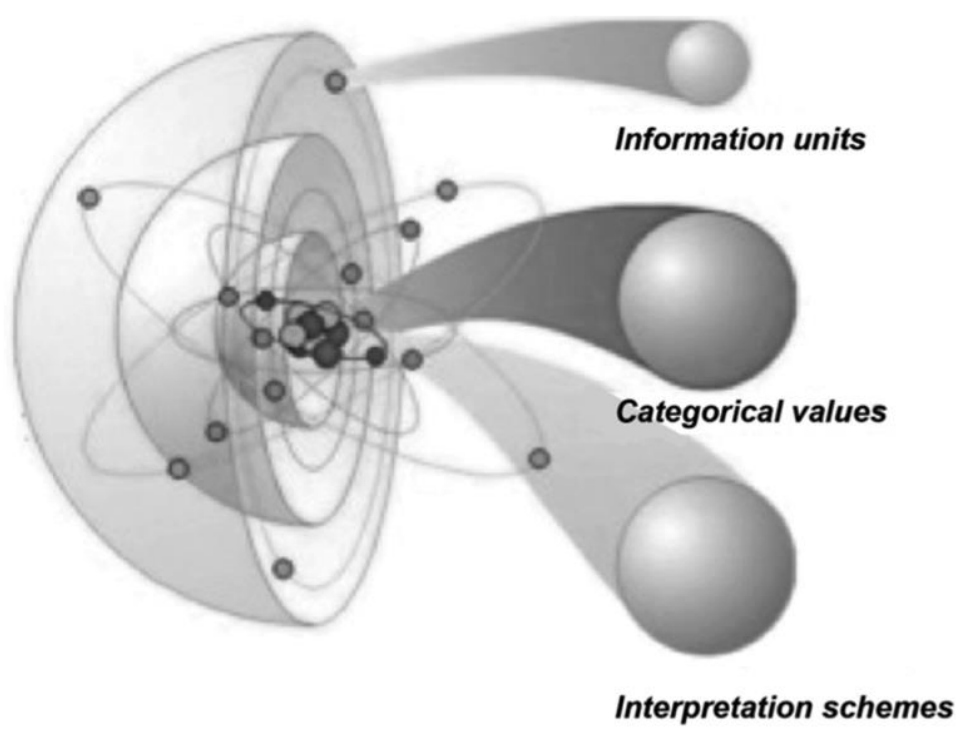

Figure 2.2.1. Representation of information variety (Barile, Saviano and Polese, 2014). ${ }^{2}$

\subsection{Collective Intelligence and Collective Knowledge System}

Starting from the theory of knowledge creating (Nonaka and Takeuchi, 1995), the cognitive systems (individuals) can have an impact on the development of a social system (as an organisation) which, in turn, can influence their beliefs. In this direction, Collective Intelligence (Lévy and Bononno, 1997) is understood as different micro-contributions to the understanding that can be provided in order to multiply, instead of summing, the intelligence of singles. When one system provides to the other its ability to solve complexity, both the knowledge of each system and the collective knowledge are increased. According to Wise, Paton, and Gegenhuber (2012), the concept of CI encompasses and surpasses many of the recent conceptualisations (such as open innovation, crowdsourcing, and wisdom of crowds) by representing the human tendency to do seemingly intelligent things in a collective manner (Malone, Laubacher and Dellarocas, 2010). Above all, this concept takes on importance with the advent of the Web 2.0 era by leveraging the collective power of users' contributions, interactions and feedback, which is the key to market dominance. A new category of techniques enables the discovery of the patterns, interrelationships and individual profiles locked in the data, which people leave behind as they browse websites, post on blogs and interact with other users (Alag, 2008). Furthermore, based on the CI concept, the Collective Knowledge Systems (CKS) (Gruber, 2008) are able to solve user problems thanks to collective intelligence phenomena based on ICT tools (analytics and research engine, etc.; see Gaeta et al., 2010). The CKS are specifically a kind of system in which small groups of proactive users produce information artefacts that can be searched by other users that need information. In such human-machine systems, both humans and machines actively contribute to the resulting intelligence.

\footnotetext{
${ }^{2}$ Image used with the permission of aSvSa. Available online at http://www.asvsa.org/ (last accessed: November 12, 2020).
} 


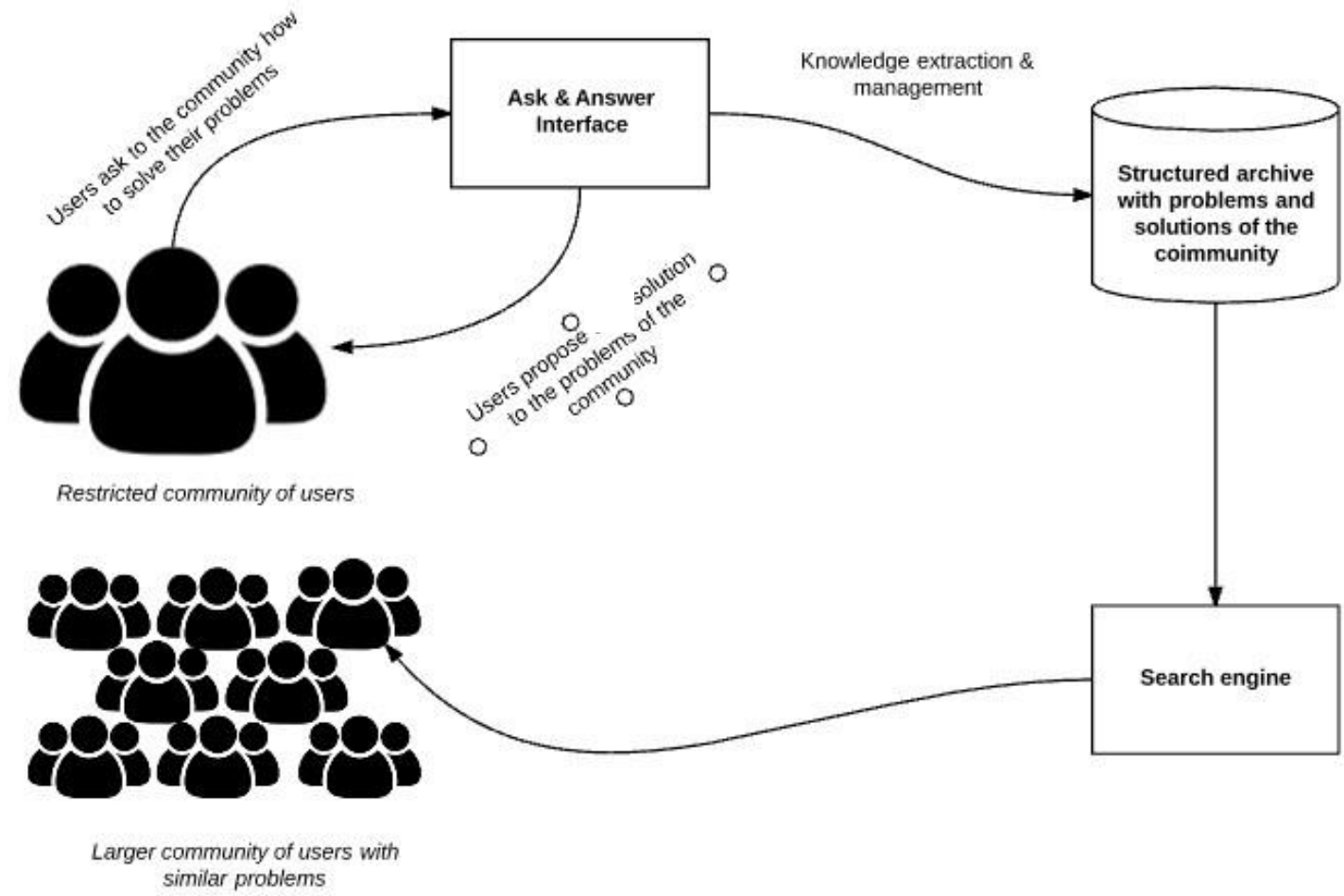

Figure 2.3.1. Example of a Collective Knowledge System. ${ }^{3}$

The CKS, as shown in Figure 2.3.1, consists of three subsystems:

1. a social system supported by information and communication technologies, which formulate a problem that can be solved by means of discussion in the community;

2. a search engine, capable of finding questions and answers in the contents generated by the social system;

3. intelligent users, capable of formulating problems by means of queries for the search engine.

Therefore, one of the key characteristics of the CKS is the presence of user-generated contents. The system can also make inferences from the user-generated contents through knowledge extraction approaches, thus producing answers and results that cannot be found explicitly in such contents, which represents emerging knowledge enabling the shift from gathered and individual intelligence to collective intelligence.

\section{A conceptual model for managing external and internal knowledge based on big data analytics and CKS: advantages and implications}

Starting from the considerations thus far mentioned, seeing the organisations as complex systems has emphasised the goal of managing and developing their knowledge, and according to the view of Viable System Approach and Systems Thinking, a conceptual model for managing external and internal knowledge based on big data approach can be presented.

\footnotetext{
${ }^{3}$ Conceived and designed by the authors on the basis of the work carried out by Gruber (2008).
} 
In particular, the model, depicted in Figure 3.1, is comprised of two sections:

1. 'human users', regarding human-human interactions;

2. 'machine processes', dedicated to automated activities carried out by software and hardware components.

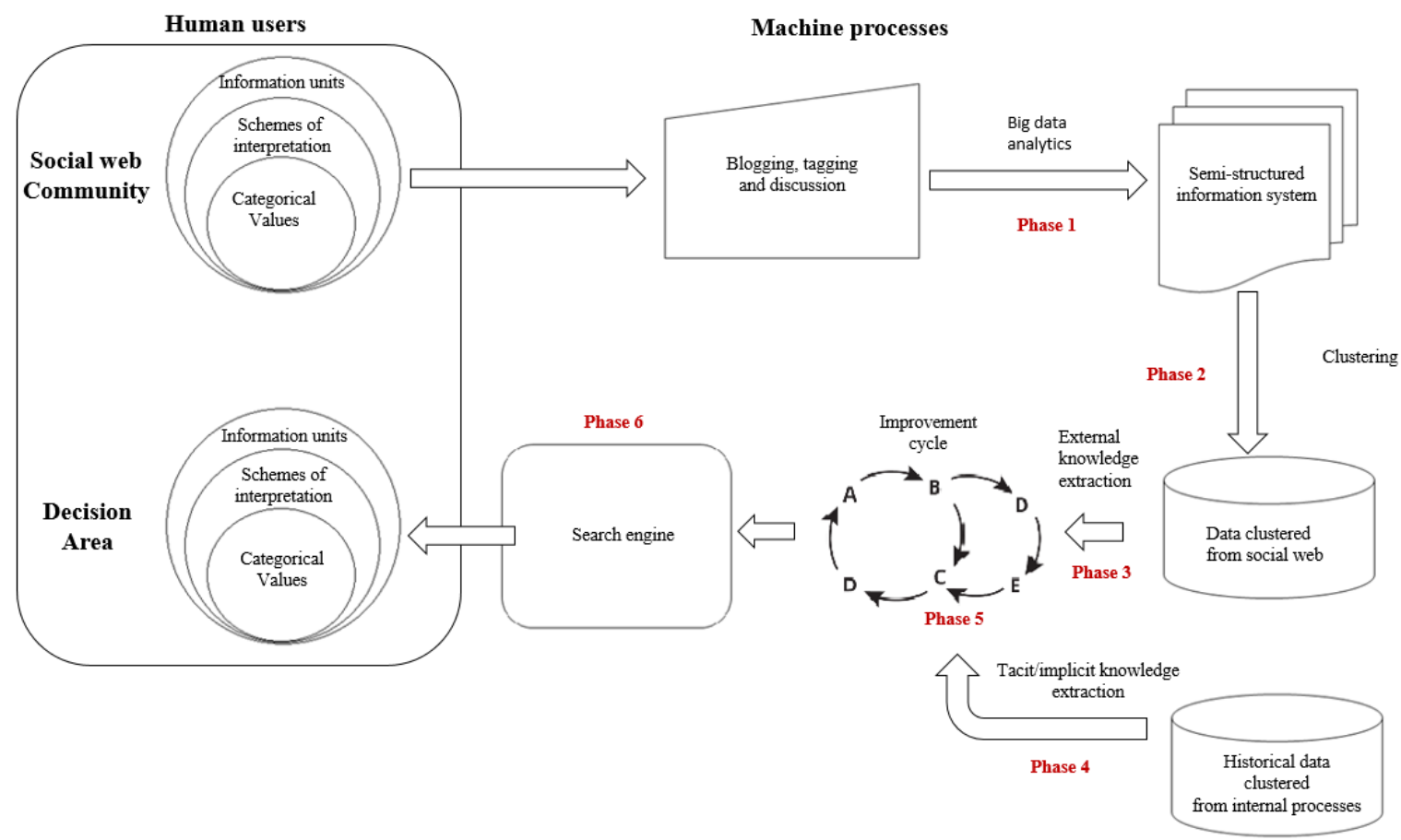

Figure 3.1. A viable framework for managing external and internal knowledge based on big data analytics and CKS. ${ }^{4}$

In this model, regarding the external knowledge and based on Gruber (2008), an important role is played by the social web communities, characterised by a determined information variety composed of information units, interpretative schemes and categorical values (Calabrese, Iandolo and Bilotta, 2011). In order to interpret and set up effectively the relationships with the multiple entities present and active in the environment, and in order to create context consonance, organisations try to exploit new forms of interaction, collaboration and knowledge sharing (Barile and Calabrese, 2011) with the social web community (Gruber, 2008) through leveraging the collaborative dimension of social software.

Therefore, in phase 1, starting from intelligent users who interact on the social web through blogging, tagging, and discussion on internet contents, it is possible to extract useful information from a large amount of data through big data analytics. In particular, this is obtained by clustering a semi-structured information system that can be managed in order to compose a repository of data clustered (Fan and Bifet, 2013) (phase 2). Thus, from this repository, it is possible to manage and exploit the knowledge derived from the environment (phase 3).

\footnotetext{
${ }^{4}$ Conceived and designed by the authors.
} 
Additionally, in order to consider and manage the internal knowledge strategically, the implicit knowledge and the explicit knowledge within the organisation have to be considered (phase 4). In this regard, the extracted or extractable knowledge obtained from the data by the organisations' information systems can be exploited and connected to the explicit knowledge. In particular, the 'procedural knowledge base', comprised of the knowledge derived from information systems on business processes, connected to a 'declarative knowledge base', comprised instead of unwritten rules and procedures that influence the organisational level, can contribute and support decision-making activities, enriching a greater degree of awareness about the internal organisation's potentialities, limits and structural characteristics (Cohen et al., 1985; Ten Berge and Van Hezewijk, 1999).

Therefore, with reference to these three different types of knowledge, respectively the 'social web', the 'procedural' and the 'declarative' knowledge, our approach will consider them in a synergic way and combine them by means of an improvement cycle, with the aim to support the decision-making processes, considering both external and internal information (phase 5).

Afterwards, a search engine (phase 6) is capable of finding questions and answers in the data clustered, generated by the social web community (Gruber, 2008) and internal processes. It offers these outputs in order to support and improve strategic decision-making activities, characterised by a high level of complexity. Consequently, this approach is able to derive inferences from user-generated content through knowledge extraction approaches, producing information that cannot be found explicitly in such contents, which represents emerging knowledge enabling the shift from gathered and individual intelligence to collective intelligence. In addition, the proposed framework is able to consider the internal knowledge, comprised of rules, procedures but also implicit information regarding the organisation's structure (Nickols, 2000). In this way, the decision-maker can align her/his information variety to the external entities, represented by the social web, and to the internal components that constitute the organisation, in order to reach a significant level of consonance, which represents potential harmonic relations, and to ensure a greater possibility of vitality for the complex system (Barile and Polese, 2010).

Considering the properties of the complex systems, this approach can offer several advantages:

- $\quad$ as for self-organisation, through the proposed approach, the system can benefit from internal knowledge (phase 4) by leveraging the influences coming from the same elements that constitute it. Thus, by using the search engine (phase 6) on contents about the internal knowledge, the system obtains answers able to highlight the ever-changing organisational traits and support the strategic decision-making processes. In this regard, the exaptation metaphor underscores that the knowledge extractable from the historical data of the organisation connected to declarative knowledge based on procedures can contribute and support the viability of the complex system, enriching a greater degree of awareness about the inner organisation's strengths, critical issues and structural characteristics;

- $\quad$ with regard to hierarchy, the identified mechanism of collective intelligence takes into account the continuous internal reorganisation due to adaptation processes in relation to the modifications needed for both inside and outside reasons by leveraging the obtained internal and external knowledge. In this way, by exploiting this newly achieved awareness, the complex system substitutes the processes to better them. It 
evolves continuously in order to increase the ability to interact with other information varieties in a more consonant way. Therefore, the vicariance concept underlines the need to align the information variety to the context, represented in this case by the social web, and to the internal components that constitute the organisation in order to establish potential harmonic relations with the different actors.

- $\quad$ continuing with the resilience, by exploiting the proposed framework, the system tries to adapt itself by considering multiple perspectives (both internal and external) with regard to uncertain environmental conditions and structural characteristics. As a bricoleur, it tries to respond to stress phenomena by adapting its information set according to its various purposes and strategic projections. Only through the phases of learning, diversifying and evolving, the system can pursue viability and ensure its continuation.

\section{Conclusion}

In a context characterised by growing turbulence, the complex systems seek viability by balancing a plurality of sub-components that react in unison with external or internal information. They are coupled with the environment they occupy and are also susceptible to minimal environmental variations. Furthermore, as seen in the previous sections, the need for a holistic approach is more evident thanks to the concepts of vicariance, bricolage and exaptation. In addition, the innovative technological approach starting from Web 2.0 can break new ground in this field. These metaphors, applicable to multidisciplinary fields (e.g., sociology, psychology, neurosciences, and biology, just to name but a few), address new aware perceptions in order to deepen the changeable nature of social systems and their complex evolution.

Accordingly, this paper has demonstrated that effective management of an organisation's internal and external knowledge requires a holistic perspective, able to clarify the role and contributions of new technologies and big data. In the same direction, the paper has underlined the existence of multiple perspectives, which the decision area of a complex system should consider. This consideration highlights the need for adopting multi- and transdisciplinary approaches with the aim to effectively provide a clear picture and framework to systemically consider the external information and the organisational structural aspects by integrating a plurality of contributions into a final unique identity of a collective intelligence/knowledge.

Reflecting upon these research streams, some implications can be derived both from theoretical and practical points of view. It is possible to state that, from a theoretical point of view, the paper has merged the Viable System Approach and the Systems Dynamics with the concepts of Collective Intelligence and Collective Knowledge System, in order to combine the systems thinking, the interpretative lens of the reality, with different research streams and perspectives related to new trends in information technology. At the same time, from the managerial point of view, the work shows a framework that can be a valid support for managing the external and internal knowledge with the aim to make the decision-maker more aware of the interventions and strategic policies to carry out.

In recognising the validity of the proposed concept, some possible future research lines can be pursued to enrich the framework proposed and expand it through a possible case study 
related to the identified issues. Therefore, the reflections herein only outline a possible conceptual path in which borders and boundaries require a better definition because of the multiple connections and influences that can be traced among the identified concepts. More specifically, further research should be devoted to effectively understanding the relation between internal/external vs. single/collective knowledge correlated to the concept of resilience and how this connection can affect the viability of complex systems.

\section{Keywords}

big data; systems thinking; collective knowledge systems; collective intelligence; viable system approach

\section{References}

Alag, S. (2008), Collective Intelligence in Action, New York, NY: Manning.

Alavi, M., and Leidner, D.E. (2001), “Review: Knowledge Management and Knowledge Management Systems: Conceptual Foundations and Research Issues", MIS Quarterly, 25 (1): 107-136.

Allee, V. (1997), The Knowledge Evolution, Oxford: Butterworth-Heinemann.

Armenia, S., Carlini, C., Onori, R., and Saullo, A.P. (2013), "Policy Modeling as a New Area for Research: Perspectives for a Systems Thinking and System Dynamics Approach?", in Proceedings of the $13^{\text {th }}$ European Academy of Management (EURAM) Conference, Istanbul, Turkey: EURAM 2013.

Armenia, S., Ferreira Franco, E., Mecella, M., and Onori, R. (2017), “Smart Model-Based Governance: From Big-Data to Future Policy Making", in F. Nonino, S. Armenia and G. Dominici (eds), Model-Based Governance for Smart Organizational Future: BSLab-SYDIC International Workshop, Rome, January 23-24 (Book of Abstract), pp. 44-53. Available online at http://bslab-symposium.net/BSLab-Sydic-2017/Book-Abstracts-BSLab-Sydic2017-final.pdf (last accessed: November 12, 2020).

Ashby, W.R. (1991), "Requisite Variety and Its Implications for the Control of Complex Systems", in G.J. Klir (ed.), Facets of Systems Science, pp. 405-417, Boston, MA: Springer. DOI: 10.1007/978-1-4899-0718-9_28.

Ashton, K. (2009), “That 'Internet of Things' Thing", Radio Frequency Identification (RFID) Journal, 22 (7): 97-114.

Barile, S., and Calabrese, M. (2011), "Business Design and Context Consonance (Business Design e Consonanza di Contesto)", Social Science Research Network (SSRN) Electronic Journal, 1-26. DOI: 10.2139/ssrn.2053618.

Barile, S., and Polese, F. (2010), "Linking the Viable System and Many-to-Many Network Approaches to Service-Dominant Logic and Service Science", International Journal of Quality and Service Sciences, 2 (1): 23-42.

Barile, S., and Saviano, M. (2008), "Le Basi del Pensiero Sistemico: La Dicotomia StrutturaSistema", in S. Barile (ed.), L'Impresa come Sistema: Contributi sull'Approccio Sistemico Vitale (ASV), pp. 63-81, Turin: Giappichelli. 
Barile, S., and Saviano, M. (2011), "Foundations of Systems Thinking: The Structure-System Paradigm", in S. Barile, C. Bassano, M. Calabrese, M.G. Confetto, P. Di Nauta, P. Piciocchi, F. Polese, M. Saviano, A. Siano, M. Siglioccolo and A. Vollero (eds), Contributions to Theoretical and Practical Advances in Management: A Viable Systems Approach (VSA), pp. 1-25, Avellino: International Printing Srl Editore.

Barile, S., and Saviano, M. (2018), "Complexity and Sustainability in Management: Insights from a Systems Perspective", in S. Barile, M. Pellicano and F. Polese (eds), Social Dynamics in a Systems Perspective, pp. 39-63, Cham, Switzerland: Springer.

Barile, S., Fulco, I., Loia, F., and Vito, P. (2018), “Un Modello di Supporto alle Decisioni Territoriali tra Analisi dei 'Sentiment' e Consonanza Sistemica”, in C. Baccarani, M. Frey, G.M. Golinelli, A. Pastore and T. Vescovi (eds), Transformative Business Strategies and New Patterns for Value Creation: Referred Electronic Conference Proceedings, pp. 257-273. Available online at https://www.sijm.it/wp-content/uploads/2018/11/FULL-PAPERVENEZIA-COMPLETO.pdf (last accessed: November 12, 2020).

Barile, S., Saviano, M., and Polese, F. (2014), "Information Asymmetry and Co-Creation in Health Care Services", Australasian Marketing Journal (AMJ), 22 (3): 205-217.

Barile, S., Saviano, M., Polese, F., and Di Nauta, P. (2012), “Il Rapporto Impresa-Territorio tra Efficienza Locale, Efficacia di Contesto e Sostenibilità Ambientale [The Firm-Territory Relationship between Local Efficiency, Context Effectiveness and Environmental Sustainability]", in S. Barile, M. Saviano, F. Polese and P. Di Nauta (2012), "Il Rapporto Impresa-Territorio tra Efficienza Locale, Efficacia di Contesto e Sostenibilità Ambientale", in Referred Electronic Conference Proceeding Convegno Sinergie "Il Territorio come Giacimento di Vitalità per l'Impresa, pp. 387-402.

Begoli, E., and Horey, J. (2012), “Design Principles for Effective Knowledge Discovery from Big Data", in 2012 Joint Working IEEE/IFIP Conference on Software Architecture and European Conference on Software Architecture, pp. 215-218. DOI: 10.1109/WICSAECSA.212.32.

Berthoz, A. (2013), La Vicariance: Le Cerveau Créateur de Mondes, Paris: Odile Jacob.

Beyer, M.A., and Laney, D. (2012), The Importance of "Big Data": A Definition, Stamford, CT: Gartner.

Calabrese, M., Iandolo, F., and Bilotta, A. (2011), "From Requisite Variety to Information Variety through the Information Theory the Management of Viable Systems", in E. Gummesson, C. Mele and F. Polese (eds), Service Dominant Logic, Network E Systems Theory and Service Science: Integrating Three Perspectives for a New Service Agenda, Online Proceedings of the 2011 Naples Forum on Service, Naples: Giannini.

Chen, C.P., and Zhang, C.Y. (2014), “Data-Intensive Applications, Challenges, Techniques and Technologies: A Survey on Big Data", Information Sciences, 275: 314-347. DOI: 10.1016/j.ins.2014.01.015.

Chen, H., Chiang, R.H., and Storey, V.C. (2012), “Business Intelligence and Analytics: From Big Data to Big Impact", Management Information Systems (MIS) Quarterly, 36 (4): 11651188.

Ciasullo, M.V., Troisi, O., Loia, F., and Maione, G. (2018), “Carpooling: Travelers' Perceptions from a Big Data Analysis", The TQM Journal, 30 (5): 554-571. DOI: 10.1108/TQM-11-20170156. 
Cohen, N.J., Eichenbaum, H., Deacedo, B.S., and Corkin, S. (1985), “Different Memory Systems Underlying Acquisition of Procedural and Declarative Knowledge", Annals of the New York Academy of Sciences, 444 (1): 54-71.

Coyle, K (2006), "Mass Digitization of Books", The Journal of Academic Librarianship, 32 (6): 641645.

Cricelli, L., and Grimaldi, M. (2008), “A Dynamic View of Knowledge and Information: A Stock and Flow Based Methodology", International Journal of Management and Decision Making, 9 (6): 686-698.

Cyert, R.M., and March, J.G. (1963), A Behavioral Theory of the Firm, Englewood Cliffs, NJ: Prentice-Hall.

De Jarnett, L. (1996), "Knowledge the Latest Thing: Information Strategy", The Executives Journal, 12 (2): 3-5.

Dominici, G., Roblek, V., and Lombardi, R. (2016), “A Holistic Approach to Comprehending the Complexity of the Post-Growth Era: The Emerging Profile", in Ş.Ş. Erçetin (ed.), Chaos, Complexity and Leadership 2014, pp. 29-42, Cham, Switzerland: Springer.

Dooley, K.J. (1997), “A Complex Adaptive Systems Model of Organization Change”, Nonlinear Dynamics, Psychology, and Life Sciences, 1 (1): 69-97.

Drucker, P.F. (1995), “The New Productivity Challenge”, Quality in Higher Education, 37: 4553.

Fan, W., and Bifet, A. (2013), "Mining Big Data: Current Status, and Forecast to the Future", ACM sIGKDD Explorations Newsletter, 14 (2): 1-5.

Forrester, J.W. (1961), Industrial Dynamics, New York/London: Massachusetts Institute of Technology and Jon Wiley and Sons.

Forrester, J.W. (1994), "System Dynamics, Systems Thinking, and Soft OR", System Dynamics Review, 10 (2-3): 245-256. DOI: 10.1002/sdr.4260100211.

Frakes, W.B., and Baeza-Yates, R. (eds) (1992), Information Retrieval: Data Structures $\mathcal{E}$ Algorithms, Englewood Cliffs, NJ: Prentice Hall.

Gaeta, M., Loia, F., Sarno, D., and Carrubbo, L. (2019), “Online Social Network Viability: Misinformation Management Based on Service and Systems Theories", International Journal of Business and Management, 1 (1): 17-35. DOI: 10.5539/ijbm.v14n1p17.

Golinelli, G.M. (2010), Viable Systems Approach (VSA): Governing Business Dynamics, Padua: CEDAM.

Gould, S.J., and Vrba, E.S. (1982), "Exaptation: A Missing Term in the Science of Form", Paleobiology, 8 (1): 4-15.

Gruber, T. (2008), “Collective Knowledge Systems: Where the Social Web Meets the Semantic Web", Web Semantics: Science, Services and Agents on the World Wide Web, 6 (1): 4-13.

Gummesson, E. (2008), “Extending the Service-Dominant Logic: From Customer Centricity to Balanced Centricity", Journal of the Academy of Marketing Science, 36 (1): 15-17.

Gummesson, E., and Mele, C. (2010), "Marketing as Value Co-Creation through Network Interaction and Resource Integration", Journal of Business Market Management, 4 (4): 181198. 
Holland, J.H. (1995), Hidden Order: How Adaptation Builds Complexity, New York, NY: AddisonWesley.

Holling, C.S. (1996), "Engineering Resilience versus Ecological Resilience", in National Academy of Engineering (ed.), Engineering Within Ecological Constraints, pp. 31-44, Washington, DC: The National Academies Press. DOI: 10.17226/4919.

Holling, C.S., and Gunderson, L.H. (2002), "Resilience and Adaptive Cycles", in L.H. Gunderson (ed.), Panarchy: Understanding Transformations in Human and Natural Systems, pp. 25-62, Washington, DC: Island Press.

Iandolo, F., Barile, S., Armenia, S., and Carrubbo, L. (2018), “A System Dynamics Perspective on a Viable Systems Approach Definition for Sustainable Value", Sustainability Science, 13: 1245-1263. DOI: 10.1007/s11625-018-0565-2.

Janssen, M., van der Voort, H., and Wahyudi, A. (2017), "Factors Influencing Big Data Decision-Making Quality", Journal of Business Research, 70: 338-345. DOI: 10.1016/j.jbusres.2016.08.007.

Johnson, J.E. (2012), "Big Data + Big Analytics = Big Opportunity", The Financial Executive, 28 (6): 50-54.

Lam, A. (2000), “Tacit Knowledge, Organizational Learning and Societal Institutions: An Integrated Framework", Organization Studies, 21 (3): 487-513. DOI: $10.1177 / 0170840600213001$.

Laudon, K.C., and Laudon, J.P. (1999), Management Information Systems, Upper Saddle River, NJ: Prentice Hall.

Laudon, K.C., and Laudon, J.P. (2011), Essentials of Management Information Systems, Upper Saddle River, NJ: Pearson.

LaValle, S., Hopkins, M.S., Lesser, E., Shockley, R., and Kruschwitz, N. (2010), “Analytics: The New Path to Value", MIT Sloan Management Review, 52 (1): 1-25.

Levin, S.A. (1998), "Ecosystems and the Biosphere as Complex Adaptive Systems", Ecosystems, 1 (5): 431-436.

Lévi-Strauss, C. (1962), La Pensée Sauvage (Vol. 289), Paris: Plon.

Lévy, P., and Bononno, R. (1997), Collective Intelligence: Mankind's Emerging World in Cyberspace, New York, NY: Perseus Books.

Liew, A. (2007), “Understanding Data, Information, Knowledge and Their InterRelationships", Journal of Knowledge Management Practice, 8 (2): 1-16.

Lincoln, Y.S., and Denzin, N.K. (1994), "The Fifth Moment", in N.K. Denzin and Y.S. Lincoln (eds), The Handbook of Qualitative Research (1 ${ }^{\text {st }}$ edn.), pp. 575-586, Thousand Oaks, CA: SAGE.

Malone, T.W., Laubacher, R., and Dellarocas, C. (2010), “The Collective Intelligence Genome”, MIT Sloan Management Review, 51 (3): 21-31.

McAdam, R., and McCreedy, S. (1999), “A Critical Review of Knowledge Management Models", The Learning Organization, 6 (3): 91-101.

McAfee, A., and Brynjolfsson E. (2012), “Big Data: The Management Revolution”, Harvard Business Review, 90 (10): 60-68.

Meadows, D.H. (2008), Thinking in Systems: A Primer, London: Chelsea Green Publishing. 
Miller, H.G., and Mork, P. (2013), "From Data to Decisions: A Value Chain for Big Data", IT Professional, 15 (1): 57-59. DOI: 10.1109/MITP.2013.11.

Mirchi, A., Madani, K., Watkins, D., and Ahmad, S. (2012), “Synthesis of System Dynamics Tools for Holistic Conceptualization of Water Resources Problems", Water Resources Management, 26 (9): 2421-2442.

Morecroft, J.D. (1983), "System Dynamics: Portraying Bounded Rationality", Omega, 11 (2): 131-142.

Nickols, F. (2000), "The Knowledge in Knowledge Management", in J.W. Cortada and J.A. Woods (eds), The Knowledge Management Yearbook 2000-2001, pp. 12-21, Oxford: Butterworth-Heinemann.

Nonaka, I., and Takeuchi, H. (1995), The Knowledge-Creating Company: How Japanese Companies Create the Dynamics of Innovation, Oxford: Oxford University Press.

O'Connor, J., and McDermott, I. (1997), The Art of Systems Thinking, San Francisco, CA: Thorsons.

Polese, F., Mele, C., and Gummesson, E. (2017), "Value Co-Creation as a Complex Adaptive Process", Journal of Service Theory and Practice, 27 (5): 926-929.

Powell, W.W., and Snellman, K. (2004), "The Knowledge Economy", Annual Review of Sociology, 30: 199-220. DOI: 10.1146/annurev.soc.29.010202.

Prescott, E.M. (2014), “Big Data and Competitive Advantage at Nielsen”, Management Decision, 52 (3): 573-601.

Reuchlin, M. (1978), “Processus Vicariants et Différences Individuelles”, Journal de Psychologie, 75: 133-145.

Rowley, J. (2007), “The Wisdom Hierarchy: Representations of the DIKW Hierarchy”, Journal of Information Science, 33 (2): 163-180.

Rubenstein-Montano, B., Liebowitz, J., Buchwalter, J., McCaw, D., Newman, B., Rebeck, K., and Team, T.K.M.M. (2001), “A Systems Thinking Framework for Knowledge Management", Decision Support Systems, 31 (1): 5-16.

Senge, P. (1990), The Fifth Discipline, New York, NY: Currency Doubleday.

Simon, H.A. (1955), "A Behavioral Model of Rational Choice", The Quarterly Journal of Economics, 69 (1): 99-118.

Stacey, R. (2003), Complex Responsive Processes in Organizations: Learning and Knowledge Creation, London: Routledge.

Sterman, J.D. (1994), “Learning in and about Complex Systems”, System Dynamics Review, 10 (2-3): 291-330.

Sterman, J.D. (2000), Business Dynamics: Systems Thinking and Modeling for a Complex World, Boston, MA: Irwin/McGraw-Hill.

Sterman, J.D. (2001), "System Dynamics Modeling: Tools for Learning in a Complex World", California Management Review, 43 (4): 8-25.

Sterman, J.D. (2012), "Sustaining Sustainability: Creating a Systems Science in a Fragmented Academy and Polarized World", in M. Weinstein and R. Turner (eds), Sustainability Science, pp. 21-58, New York, NY: Springer. DOI: 10.1007/978-1-4614-3188-6_2. 
Svyantek, D.J., and Brown, L.L. (2000), "A Complex-Systems Approach to Organizations", Current Directions in Psychological Science, 9 (2): 69-74.

Ten Berge, T., and Van Hezewijk, R. (1999), "Procedural and Declarative Knowledge: An Evolutionary Perspective", Theory \& Psychology, 9 (5): 605-624.

Troisi, O., D'Arco, M., Loia, F., and Maione, G. (2018), “Big Data Management: The Case of Mulino Bianco's Engagement Platform for Value Co-Creation", International Journal of Engineering Business Management, 10: 1-8. DOI: 10.1177/1847979018767776.

Uddin, M.F., and Gupta, N. (2014), "Seven V's of Big Data: Understanding Big Data to Extract Value", in Proceedings of the 2014 Zone 1 Conference of the American Society for Engineering Education, pp. 1-5. DOI: 10.1109/ASEEZone1.2014.6820689.

von Bertalanffy, L. (1952), Problems of Life: An Evaluation of Modern Biological Thought, New York, NY: Wiley \& Sons.

von Bertalanffy, L. (1956), “A Biologist Looks at Human Nature”, The Scientific Monthly, 82 (1): 33-41.

von Bertalanffy, L. (1967), "General Theory of Systems: Application to Psychology", Social Science Information, 6 (6): 125-136. DOI: 10.1177/053901846700600610.

Wise, S., Paton, R.A., and Gegenhuber, T. (2012), "Value Co-Creation through Collective Intelligence in the Public Sector: A Review of US and European Initiatives", Vine, 42 (2): 251-276.

Wu, J., Dai, L., Chiclana, F., Fujita, H., and Herrera-Viedma, E. (2018), “A Minimum Adjustment Cost Feedback Mechanism-Based Consensus Model for Group Decision Making under Social Network with Distributed Linguistic Trust", Information Fusion, 41: 232-242.

Wu, X., Zhu, X., Wu, G.Q., and Ding, W. (2014), “Data Mining with Big Data”, IEEE Transactions on Knowledge and Data Engineering, 26 (1): 97-107.

Yolles, M. (2000), “Organisations, Complexity, and Viable Knowledge Management", Kybernetes, 29 (9-10): 1202-1222.

Yolles, M. (ed.) (2006), Organizations as Complex Systems: An Introduction to Knowledge Cybernetics, Greenwich, CT: Information Age Publishing.

Zaslavsky, A., Perera, C., and Georgakopoulos, D. (2013), "Sensing as a Service and Big Data", in Proceedings of the International Conference on Advances in Cloud Computing (ACC), arXiv:1301.0159.

Zikopoulos, P., and Eaton, C. (2011), Understanding Big Data: Analytics for Enterprise Class Hadoop and Streaming Data, New York, NY: McGraw-Hill Osborne Media. 